\title{
Género Pandoraea
}

Introducción. El género Pandoraea fue establecido por Coenye y col en el año $2000^{1}$, como resultado de un re-estudio a un grupo de microorganismos representado por varias especies estrechamente relacionadas entre sí y no definitivamente identificadas a nivel de especie, llamado "Complejo Burkholderia cepacia", Ralstonia pickettii y Ralstonia paucula y que son, generalmente, resistentes a múltiples antimicrobianos. Pandoraea comprende patógenos reconocidos en pacientes con enfermedades crónicas del pulmón, particularmente, con fibrosis quística (FQ).

Taxonomía: El género Pandoraea spp denominado anteriormente por el Center for Disease Control (CDC) grupo 2 (WO-2), actualmente tiene nueve especies. A algunas de éstas se les dio nombre, mientras que a las otras se les designa como "genomovars" de $B$. cepacia. Hay cinco especies nominadas: P. apista, P. pulmonicola, $P$. pnomenusa, $P$. sputorum, $P$. norimbergensis.

Pandoraea pnomenusa ha sido la especie más aislada desde hemocultivo en el CDC, lo cual sugiere un potencial de esta especie en particular para causar enfermedades invasoras.

Bacteriología: El complejo B. cepacia,
Ralstonia sp y Pandoraea sp, comprende bacilos gramnegativos, aerobios estrictos, no esporulados, con uno o más flagelos polares. La mayoría se comporta como oxidasa, catalasa y movilidad positivas (con excepción de $B$. mallei que es inmóvil), crece en McConkey y es resistente a colistín $(10 \mu \mathrm{g})$.

El género Pandoraea sp incluye bacilos gramnegativos, aerobios estrictos, no fermentadores de glucosa y móviles, gracias a la presencia de uno a ocho flagelos polares. Crecen bien en agar sangre, en Mc Conkey y en caldo nutritivo a $33-35^{\circ} \mathrm{C}$. En la tinción de Gram se observan bacilos gramnegativos, derechos o algo curvos y pueden presentar tinción bipolar. La colonia es circular, grisácea, observándose mejor a las 48 horas de incubación. Son asacarolíticos, indol, esculina y gelatina negativos.

Identificación: (Tablas 1 y 2).

Hábitat e importancia clínica: Las infecciones de las vías respiratorias, en personas con FQ, se caracterizan por exacerbaciones agudas intercurrentes con fiebre, pérdida de peso, aumento de la tos, cambio en el volumen, color o apariencia del esputo, aumento de la frecuencia respiratoria y aparición de infiltrados en las radiografías del tórax. La infección pulmonar crónica es aún una de las causas más importantes de muerte. Los primeros reportes de infección de pacientes con FQ con B. cepacia aparecieron a finales de los años 70 y comienzos de los 80 en Toronto, Canadá. El deterioro rápido y progresivo de la función respiratoria, llamado "síndrome cepacia", se caracteriza por neumonía y sepsis. Pandoraea sp es un patógeno aislado desde pacientes con septicemias y enfermedades crónicas del pulmón, particularmente, en aquellos pacientes con FQ. También se ha encontrado en alimentos y suelos. Pseudomonas aeruginosa y Staphylococcus aureus son los microorganismos más comúnmente aislados en pacientes con FQ. Las infecciones debidas al complejo B. cepacia son menos frecuentes pero se asocian con infecciones cruzadas y la posibilidad de un síndrome cepacia. En un estudio realizado en Bélgica, en una población con FQ, colonizada con el complejo B. cepacia, se encontró, hasta el momento, un rango de colonización bajo y estable, pero el impacto en reducir la sobrevida puede ser alto ${ }^{3,4}$. Ha sido descrita la transmisión entre pacientes con FQ, y la eventualidad de que se disemine en la comunidad constituye siempre una preocupación.

Susceptibilidad in vitro: Estudios de sus-

\begin{tabular}{|c|c|c|c|c|c|c|c|c|c|c|c|}
\hline Mov & Ox & Cat & McC & Col & Microorganismos & Lactosa & Glucosa & Lisina & Urea & Citrato de & Simmons \\
\hline \multirow[t]{3}{*}{+} & + & + & + & $R$ & Complejo Burkholderia & + & + & \pm & - & & \pm \\
\hline & & & & & Ralstonia & \pm & \pm & - & + & & + \\
\hline & & & & & Pandoraea & - & \pm & - & \pm & & + \\
\hline
\end{tabular}

\begin{tabular}{|c|c|c|c|c|c|}
\hline Pandoraea & Oxidasa & Nitratasa & Urea de Christensen & Crecimiento a $42{ }^{\circ} \mathrm{C}$ & Crecimiento en SS agar \\
\hline P. apista & + & - & \pm & + & + \\
\hline P. pulmonicola & + & - & - & + & + \\
\hline P. sputorum & + & + & - & + & + \\
\hline P. pnomenusa & + & \pm & + & + & + \\
\hline P. norimbergensis & + & - & - & - & - \\
\hline
\end{tabular}




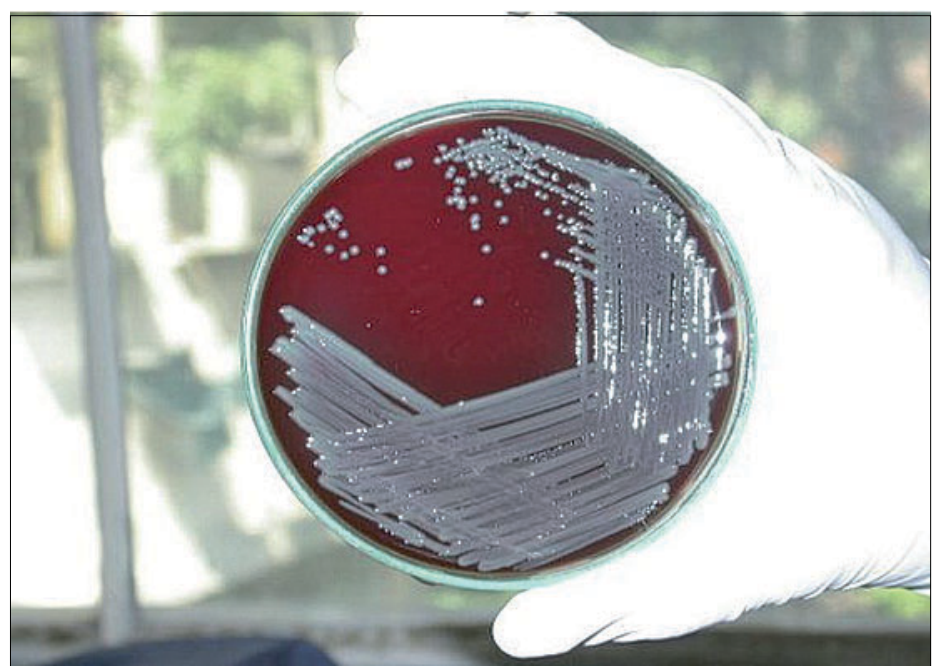

Figura 1. Colonia de Pandoraea sp en agar sangre.

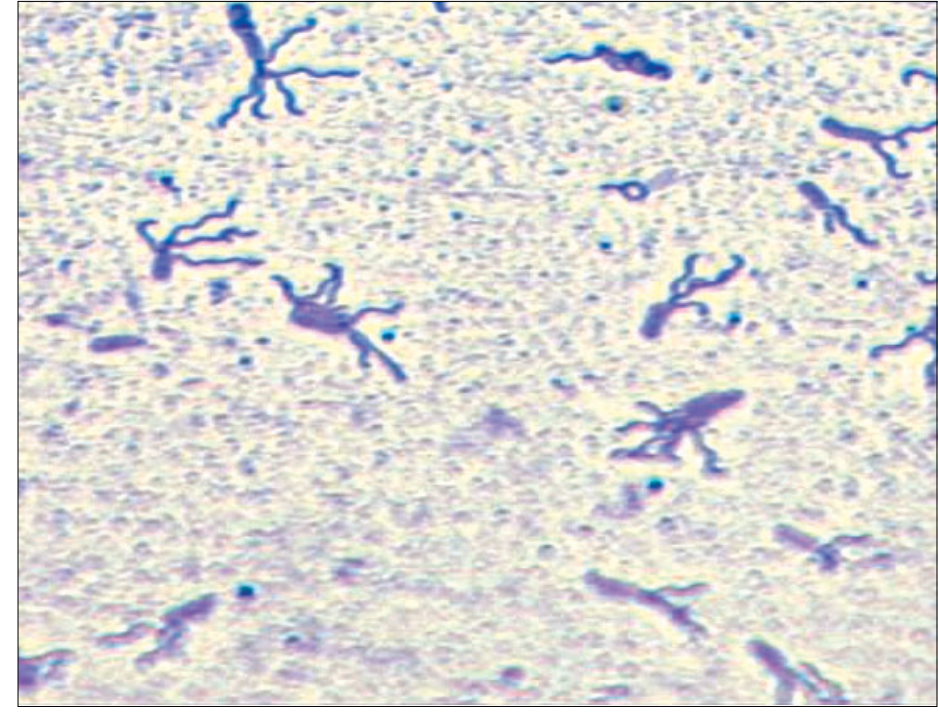

Figura 2. Se observan flagelos polares. ceptibilidad hechos en el $\mathrm{CDC}^{2}$ demostraron que Pandoraea exhibe diversos patrones de susceptibilidad. Todos los aislados fueron resistentes a ampicilina y cefazolina y la mayoría resistente a cefalosporinas de espectro extendido, aztreonam, piperacilina y aminoglucósidos. Es variable para fluoroquinolonas y presenta un patrón singular de resistencia a carbapenems: son resistentes a meropenem pero susceptibles a imipenem ${ }^{1,4}$. En un estudio reciente efectuado en Alemania, se ha encontrado una cepa de $P$. pnomenusa resistente a imipenem ${ }^{5}$, lo que hace importante su identificación hasta el nivel de especie.

\section{Referencias}

1.- Coenye T, Falsen E, Hoste B, Ohlén M, Goris J, Govan J R W, et al. Description of Pandoraea gen. nov. with Pandoraea apista sp. nov., Pandoraea pulmonicola sp. nov., Pandoraea pnomenusa sp. nov., Pandoraea sputorum sp. nov. and Pandoraea norimbergensis comb. nov. Int J Syst Evol Microbiol 2000; 50: 887-99.

2.- Daneshvar M I, Hollis D G, Steigerwalt A G, Whitney A M, Spangler L, Douglas M P, et al. Assignement of CDC Weak Oxidizer Group 2 (WO-2) to the genus Pandoraea and characterization of three new Pandoraea genomospecies. J Clin Microbiol 2001; 39: 1819-26.
3.- De Boeck K, Malfroot A, Van Schil L, Lebecque P, Knoop C, Govan JRW et al, on behalf of the Belgian Burkholderia cepacia study group. Epidemiology of Burkholderia cepacia complex colonisation in cystic fibrosis patients. Eur Respir J 2004; 23 : 851-6.

4.- Stryjewski M E, LiPuma J J, Messier R H Jr, Reller L B, Alexander B D. Sepsis, multiple organ failure, and death due to Pandoraea pnomenusa infection after lung transplantation. J Clin Microbiol 2003; 41: 2255-7.

5.- Schneider I, Queenan A M, Bauernfeind A. Novel carbapenem-hydrolyzing oxacillinase OXA-62 from Pandoraea pnomenusa. Antimicrob Agents Chemother 2006; 50: 1330-5. 